\title{
STUDI KASUS LABORATORIUM PENDIDIKAN AGAMA ISLAM DI SMAN 3 BANDUNG
}

\author{
CASE STUDY OF ISLAMIC RELIGIOUS EDUCATION LABORATORY (PAI \\ LABORATORY) AT SMAN 3 BANDUNG
}

\author{
Achmad Dudin \\ Pusat Penelitian dan Pengembangan Kemeneterian Agama RI. \\ Jl. M.H. Thamrin No. 6, Jakarta Pusat \\ editor: achmad.dudin@gmail.com
}

Naskah Diterima: 17 Maret 2018; Direvisi: 6 April 2018; Disetujui: 29 April 2018

\begin{abstract}
Islamic Religious Education (Pendidikan Agama Islam /PAI) is provided by following the guidance that religion shall be taught to human beings with a vision of manifesting pious people who only afraid of Allah SWT and have noble morality, and aims to produce people who are honest, fair, virtuous, ethical, respectful, disciplined, harmonious and productive, both personally and socially. The demands of such vision promote the development of PAI laboratory in accordance with the relevant education level. This study aims to evaluate the PAI laboratory at schools from the point of view of standard level, utilization, assessment of learners and determinants of PAI laboratory management. The method deployed in this research is qualitative evaluative through a case study carried out at SMAN 3 Bandung commenced as of July until December 2016. The research findings indicate that the PAI laboratory of SMAN 3 Bandung has reached an adequate level of standard and utilization in the management of the said PAI laboratory. This can be understood by the existence of positive assessment by the students and some supports delivered for management factors of the PAI laboratory of SMAN 3 Bandung. Furthermore, in this study, it is recommended the need of maintaining and improving the level of standard, utilization, and supporting factors of PAI laboratory management, in order for it to function effectively and optimally.
\end{abstract}

Keywords: Laboratory; management; religious education; standard

\begin{abstract}
Abstrak
Pendidikan Agama Islam (PAI) diberikan dengan mengikuti tuntunan bahwa agama diajarkan kepada manusia dengan visi untuk mewujudkan manusia yang bertakwa kepada Allah SWT dan berakhlak mulia, serta bertujuan untuk menghasilkan manusia yang jujur, adil, berbudi pekerti, etis, saling menghargai, disiplin, harmonis dan produktif, baik personal maupun sosial. Tuntutan visi ini mendorong dikembangkannya laboratorium PAI sesuai dengan jenjang pendidikan. Penelitian ini bertujuan untuk mengevaluasi laboratorium PAI di sekolah dilihat dari tingkat standar, pemanfaatan, penilaian peserta didik dan faktor penentu pengelolaan laboratorium PAI. Metode dalam penelitian ini adalah kualitatif evaluatif, dengan studi kasus di SMAN 3 Bandung pada bulan Juli hingga Desember 2016. Hasil penelitian menunjukkan bahwa laboratorium PAI SMAN 3 Bandung telah mencapai tingkat standar, dan pemanfaatan yang memadai dalam pengelolaan laboratorium PAI. Hal itu dapat di pahami dengan adanya penilaian yang positif dari siswa dan dukungan terhadap faktor pengelolaan laboratorium PAI SMAN 3 Bandung. Selanjutnya dalam penelitian ini direkomendasikan perlunya mempertahankan dan meningkatkan tingkat standar, pemanfaatan, dan faktor pendukung pengelolaan laboratorium PAI, agar fungsinya efektif dan lebih maksimal.
\end{abstract}

Kata kunci: Laboratorium; Pendidikan agama; Pengelolaan; Standar 


\section{PENDAHULUAN}

Dalam Peraturan Pemerintah Nomor 55 tahun 2007, dijelaskan bahwa pendidikan agama merupakan pendidikan yang memberikan pengetahuan dan membentuk sikap, kepribadian, dan keterampilan peserta didik dalam mengamalkan ajaran agamanya, yang dilaksanakan sekurang-kurangnya melalui mata pelajaran/kuliah pada semua jalur, jenjang, dan jenis pendidikan. ${ }^{1}$ Pendidikan agama ini sekurang-kurangnya dilaksanakan melalui mata pelajaran ataupun kuliah pada semua jurusan, semua jenjang, serta semua jenis pendidikan. Manfaat pendidikan agama sangat besar bagi terciptanya nila-nilai serta norma-norma kebaikan yang berlandaskan ajaran agama dalam setiap pribadi warga negara. Secara umum nilai-nilai ini sangat penting dalam kehidupan agar tercipta negara Indonesia yang makmur, adil, dan sejahtera. ${ }^{2}$

Agar pendidikan agama dapat memberikan pengetahuan, membentuk sikap, kepribadian, dan keterampilan peserta didik dalam mengamalkan ajaran agamanya, maka dalam implementasinya perlu dikelola dengan sebaik-baiknya, diantaranya melalui laboratorium PAI. Laboratorium PAI merupakan tempat belajar mengajar melalui media praktikum yang dapat menghasilkan pengalaman belajar dimana para siswa dapat berinteraksi dengan berbagai alat dan bahan untuk mengobservasi gejala-gejala yang dapat diamati secara langsung dan membuktikan sendiri sesuatu yang dipelajari. Pengelolaan laboratorium PAI boleh dibilang barang langka, bila dibandingkan dalam pengelolaan laboratorium IPA dan Bahasa. Menurut Haidar, pendidikan agama Islam membutuhkan sarana dan fasilitas. Bila ada laboratorium IPA, laboratorium Biologi, laboratorium bahasa, maka sekolah juga membutuhkan laboratorium agama di samping adanya masjid. ${ }^{3}$

${ }^{1}$ Peraturan Pemerintah Nomor 55 tahun 2007 tentang pendidikan Agama dan Keagamaan, Bab I Ketentuan Umum, Pasal 1.

${ }^{2}$ Adi Kategones. 2017. Pengertian dan Manfaat Pendidikan Agama, dalam: http://dbagus.com/pengerti an-dan-manfaat-pendidikan-agama (diakses 28 Desember 2017).

${ }^{3}$ Haidar Putra Daulay dan Nurgayapasa. 2012. Pendidikan Islam Dalam mencerdaskan bangsa. Jakarta: Rineka Cipta, h. 39.
Pengelolaan pembelajaran PAI melalui laboratorium kiranya dapat menghasilkan pengalaman belajar yang dibutuhkan siswa untuk dapat menguasai materi pelajaran, mempraktekkan dan pembiasaan sikap yang baik bagi siswa. Melalui laboratorium PAI, siswa dapat berinteraksi dengan berbagai alat dan bahan untuk mengobservasi gejala-gejala yang dapat diamati secara langsung dan membuktikan sendiri sesuatu yang dipelajari. Pengelolaan laboratorium PAI di sekolah perlu diperhatikan kualitas pengelolaannya, dilihat dari tingkat stardar pengelolaannya, pemanfaatan, dan faktor penentu pengelolaan laboratorium PAI.

Dalam kenyataan laboratorium di sekolah sangat dibutuhkan dalam mendukung keberhasilan pembelajaran. Hasil penelitian Bait al Ta'mirul Khikmah tahun 2011 menyebutkan bahwa laboratorium biologi Madrasah Aliyah Negeri di Kabupaten Tegal memiliki daya dukung yang baik $(71 \%)$ dalam menunjang KTSP. ${ }^{4}$ Hasil penelitian Rizka Maratush Sholihah tahun 2013 menyebutkan bahwa laboratorium kimia di SMA Negeri sekota Yogyakarta dimanfaatkan secara efektif dalam pembelajaran kimia. Laboratorium digunakan dengan baik pada pembelajaran kimia dengan frekuensi pemanfaatan laboratorium $66,67 \% .^{5}$ Selanjutnya hasil penelitian Nurhidayah Tusiyam tahun 2011 menyebutkan bahwa Pemanfaatan laboratorium Biologi kelas XI IPA Semester 1 di MAN Kendal sangat dibutuhkan dalam pembelajaran biologi dalam kegiatan praktikum, namun pemanfaatan laboratorium biologi dalam kegiatan praktikum belum maksimal untuk mencapai standar kompetensi pelajaran Biologi kelas XI IPA Semester 1di MAN Kendal. ${ }^{6}$

${ }^{4}$ Baeti Ta'mirul Khikmah. 2011. "Daya dukung laboratorium Biologi Madrasah Aliyah Negeri Di Kabupaten Tegal dalam Menunjang Pelaksanaan KTSP (Kurikulum Tingkat Satuan Pendidikan)", Skripsi. Semarang: Fakultas Tarbiyah IAIN Walisongo, h. vi.

${ }^{5}$ Rizka Maratush Sholihah. 2013. "Efektifitas Pemanfaatan Laboratorium dalam Pembelajaran kimia di SMAN Se Kota Yogyakarta Tahun Ajaran 2012/2013". Skripsi, Fakultas sain dan Teknologi UIN Sunan Kalijogo.

${ }^{6}$ Siti Nur Hidayah Tusiyam., 2011.’Pemanfaatan Laboratorium Biologi untuk mencapai Standar Kompetensi Pembelajaran Biologi KelasXI IPA Semester I di MAN Kendal”, Skripsi, Fakultas Tarbiyah IAIN Walisongo, 2011. 
Hasil penelitian tersebut menunjukkan bahwa laboratorium mempunyai kemanfaatan yang baik untuk mendukung pembelajaran. Adapun bagaimana model pemanfaatan laboratorium PAI penting dilakukan penelitian. Dengan penelitian akan diketahui sejauhmana sekolah telah memanfaatkan laboratorium PAI sebagai wujud perhatian terhadap pengelolaan laboratorium PAI di sekolah sesuai amanat Menteri Agama. Karena pengelolaan laboratorium PAI telah diatur dalam Keputusan Menteri Agama (KMA) Nomor 211 Tahun 2011 yang membahas tentang Pedoman Pengembangan Standar Nasional PAI pada Sekolah.

Dalam ketentuan Laboratorium PAI di sekolah, sebagaimana tertuang dalam KMA tersebut, disebutkan bahwa, sekolah harus menyediakan prasarana Laboratorium Pendidikan Agama Islam yang berfungsi sebagai tempat peserta didik untuk mencari informasi digital tentang Islam dan melaksanakan praktek keterampilan keagamaan, dan kegiatan lainnya yang mendukung pembelajaran PAI, baik berbentuk kegiatan intra kurikuler maupun ekstrakurikuler. Prasarana Laboratorium Pendidikan Agama Islam merupakan bangunan/ruangan yang disediakan khusus untuk keperluan tersebut di atas. Luas minimum bangunan prasarana ibadah adalah $56 \mathrm{~m}^{2}(8 \times 7 \mathrm{~m})$, kedap suara, beralaskan karpet, daya listrik minimal 900 watt, dan dilengkapi sarana-sarana tertentu yang harus dimiliki laboratorium PAI. ${ }^{7}$

Dilihat dari tingkat kebermanfaatan, Laboratorium Pendidikan Agama Islam di Sekolah menurut keputusan menteri tersebut harus difungsikan untuk: (1) Mendukung proses pembelajaran PAI dalam meningkatkan keimanan melalui pemberian, pemupukan, dan pengembangan pengetahuan, penghayatan, pengamalan, pembiasaan, serta pengalaman peserta didik tentang Agama Islam sehingga menjadi manusia muslim yang terus meningkat keimanan dan ketakwaannya kepada Allah SWT; (2) Menyediakan alat peraga dan laboratorium untuk melengkapi metode dan strategi penguatan akidah, pembiasaan akhlak

\footnotetext{
${ }^{7}$ Keputusan Menteri Agama Nomor 211 Tahun 2011 tentang Pedoman Pengembangan Standar Nasional Pendidikan Agama Islam pada Sekolah. (Jakarta: Kementerian Agama, 2011).
}

mulia, dan kualitas beribadah; dan (3) Memberi keterampilan dan pelatihan mengajar bagi guru PAI dengan media Teknologi Informasi dan Komunikasi (TIK). Adapun pemanfaatan laboratorium PAI dalam peraturan menteri disebutkan sebagai: (1) Penunjang kegiatan pembelajaran PAI; (2) Sarana visualisasi konsep-konsep agama Islam; (3) Sarana praktik pembelajaran agama Islam; (4) Model imitasi pelaksanaan ibadah; dan (5) Pengolahan bahan dakwah.

Laboratorium PAI di sekolah harus kelola dengan baik agar dapat mempermudah pembelajaran PAI yang dapat menghasilkan pengalaman belajar yang dibutuhkan peserta didik baik dalam bentuk pembiasaan sikap, mempraktekkan ajaran agama, termasuk penguasaan materi PAI melalui multi media, dan lain lain dalam rangka membantu pencapaian prestasi belajar peserta didik sesuai yang diharapkan, baik prestasi akademik maupun prestasi non akademik peserta didik. Dengan pengelolaan laboratorium PAI yang dapat memenuhi peraturan menteri tersebut, maka keberadaan laboratorium PAI akan dapat meningkatkan mutu pendidikan agama Islam di sekolah. Oleh karena itu pengelolaan laboratorium PAI secara professional di sekolah merupakan hal strategis dilakukan untuk meningkatkan mutu pembelajaran PAI yang lebih baik.

Berdasarkan pemahaman baik dari hasil penelitian yang menunjukkan bahwa laboratorium mempunyai kemanfaatan yang baik untuk mendukung pembelajaran, dan keberadaan laboratorium PAI di sekolah yang sejak tahun 2011 telah diatur dalam PMA, maka untuk melihat sejauhmana laboratorium PAI telah diselenggarakan di sekolah dilihat dari tingkat standar, pemanfaatan, penilaian peserta didik dan faktor penentu pengelolaan laboratorium PAI, kiranya penting dilakukan penelitian. Dengan penelitian ini akan diketahui sejauh mana sekolah telah menyelenggarakan laboratorium PAI sebagai wujud perhatian terhadap pengelolaan laboratorium PAI di sekolah sesuai amanat Menteri Agama.

Rumusan Masalah penelitian ini adalah sejauh mana laboratorium PAI telah diselenggarakan di sekolah dilihat dari tingkat standar, pemanfaatan, penilaian peserta didik 
dan faktor penentu pengelolaan laboratorium PAI.

Penelitian ini bertujuan untuk mengevaluasi laboratorium PAI di sekolah (SMAN 3 Bandung) dilihat dari tingkat standar, pemanfaatan, penilaian peserta didik dan faktor penentu pengelolaan laboratorium PAI. Adapun manfaat penelitian ini adalah untuk bahan masukan kebijakan yang dapat meningkatkan mutu pembelajaran PAI di sekolah melalui pengelolaan laboratorim PAI secara professional. Hasil penelitian ini juga bermanfaat untuk para pimpinan dan guru pendidikan agama Islam di sekolah dalam peningkatan mutu pengelolaan laboratorim PAI di sekolah.

\section{Kerangka Teori}

Studi evaluasi merupakan proses pengumpulan data secara ilmiah yang hasilnya dapat digunakan sebagai bahan pertimbangan untuk pengambilan keputusan dalam menentukan alternatif kebijakan. Evaluasi sendiri merupakan proses analisa sejumlah rencana dengan maksud untuk membandingkan kekuatan dan kelemahannya dan temuan-temuan tersebut dianalisa dengan kerangka kerja yang logis. Esensi evaluasi adalah membuat taksiran melalui perbandingan kekuatan dan kelemahan pelaksanaan suatu kegiatan. ${ }^{8}$ Worthen mengemukakan garis besar tujuan evaluasi sebagai berikut: (1) mengetahui prosedur-prosedur perencanaan program, dan atau produk; (2) meningkatkan prosedurprosedur, program-program dan atau produk yang telah ada; (3) menilai keadaan atau prosedur-prosedur rencana, program dan atau produk. $^{9}$

Langkah-langkah penelitian evaluasi menurut Stufflebeam, adalah: (1) melukiskan atau menggambarkan aktivitas yang dievaluasi, keputusan tentang aktifitas yang akan dijalankan, informasi yang diperlukan untuk melayani keputusan tersebut, dan kebijakan

${ }^{8}$ George I Sanchez. 2003. Educational Psychology. Texas: College of Educational The University of Texas, h. 2.

${ }^{9}$ Blaine R. Worthen dan James R. Sanders. 2011. A highly esteemed and comprehensive overview of program evaluation that covers common approaches, models, and methods. Western Michigan University; Utah State University, h.6. yang akan menentukan perolehan dan penyediaan informasi; (2) memperoleh informasi yang diperlukan; (3) menyampaikan informasi tersebut kepada mereka yang akan membuat keputusan. ${ }^{10}$ Adapun dalam studi ini bertujuan mengevaluasi laboratorium, terutama evaluasi terhadap laboratorium PAI di sekolah.

Dari pemahaman tersebut di atas dapat dinyatakan bahwa yang dimaksud evaluasi dalam penelitian ini adalah penilaian tentang keadaan atau prosedur-prosedur rencana, program dan atau produk dari laboratorium PAI di sekolah, untuk selanjutnya dilakukan analisis terhadap temuan-temuan sebagai bahan pertimbangan untuk pengambilan keputusan atau alternative kebijakan, terutama untuk peningkatan kualitas pembelajaran PAI.

Dalam upaya peningkatan kualitas pembelajaran, sangat diperlukan laboratorium sebagai tempat berlatih dan untuk mengadakan percobaan serta pengamatan. Laboratorium memiliki peranan dalam proses pembelajaran, yaitu laboratorium untuk mengembangkan kemampuan berfikir, karena hal itu berarti laboratorium telah dijadikan sebagai wahana untuk learning how to learn. ${ }^{11}$

Laboratorium penting bagi suatu lembaga pendidikan, dengan beberapa alasan: (1) Keaktifan seorang peserta didik tidak akan bisa terwujud tanpa adanya media, dan media tersebut adalah laboratorium; (2) Kegiatankegiatan yang berpusat pada pengembangan keterampilan proses, keterampilan motorik, dan pembentukan sikap ilmiah (khususnya pengembangan minat untuk melakukan penyidikan, penelitian-penelitian lingkungan dan minat untuk mempelajari alam secara mendalam) tidak akan bisa terwujud tanpa adanya laboratorium; dan (3) Sikap mandiri peserta didik dalam memahami pelajaran hanya bisa dibangun dengan adanya laboratorium. Dengan melihat begitu banyaknya manfaat laboratorium, maka bisa dibilang memiliki laboratorium adalah keniscayaan bagi setiap lembaga pendidikan. Dengan kata lain, saat ini keberadaan laboratorium bisa dibilang

${ }^{10}$ Daniel, L Stufflebeam. 1977. Educational Evaluation Decision Making. Itasca. Illinois: F.E. PeacockPubliser, Inc, h. 215.

${ }^{11}$ Wiyanto. 2008. Menyiapkan Guru Sains Mengembangkan Kompetensi Laboratorium. Semarang: UNNES Pres, cet. 1, h. 35. 
sebagai sebuah tuntutan seiring dengan perkembangan dalam pengajaran dan pengembangan kurikulum yang semakin kompleks. $^{12}$

Laboratorium memiliki beberapa pengertian, diantaranya, dalam Kamus Besar Bahasa Indonesia disebutkan bahwa laboratorium adalah tempat atau kamar dan sebagainya yang dilengkapi dengan peralatan untuk mengadakan percobaan (peyelidikan dan sebagainya). ${ }^{13}$ Menurut Direktorat Pendidikan Menengah Umum, laboratorium adalah tempat melakukan percobaan dan penyelidikan. Tempat ini dapat merupakan suatu ruangan tertutup, kamar, atau ruangan terbuka, misalnya kebun. Dalam pengertian yang terbatas laboratorium ialah suatu ruangan yang tertutup tempat melakukan percobaan dan penyelidikan.

Mustopha sebagaimana dikutip Anonim bahwa laboratorium merupakan tempat riset ilmiah, eksperimen, pengukuran ataupun pelatihan ilmiah dilakukan. Laboratorium biasanya dibuat untuk memungkinkan dilakukannya kegiatan-kegiatan tersebut secara terkendali. ${ }^{14}$ Menurut Widyarti, "laboratorium adalah suatu ruangan tempat melakukan kegiatan praktek atau penelitian yang ditunjang oleh adanya seperangkat alat-alat laboratorium serta adanya infrastruktur laboratorium yang lengkap". ${ }^{15}$ Wirjosoemarto dkk, menjelaskan bahwa pada konteks proses belajar mengajar sains di sekolah-sekolah seringkali istilah laboratorium diartikan dalam pengertian sempit yaitu suatu ruangan yang didalamnya terdapat sejumlah alat-alat dan bahan praktikum". ${ }^{16}$

Dari pemahaman teori tersebut dapat dipahami bahwa yang dimaksud laboratorium

${ }^{12}$ Richard Decaprio. 2013. Tips Mengelola Laboratorium Sekolah. Yogjakarta: DIVA press, h. 2022.

${ }^{13}$ Departemen Pendidikan Nasional. Kamus Besar Bahasa Indonesia. Jakarta: Balai Pustaka, edisi ke-3, h. 621.

${ }^{14}$ Mustopha Awan. 2000. Pengertian dan Fungsi Laboratorium. dalam https://wanmustafa.word press.com/2011/06/12/pengertian-dan-fungsi-laboratori um/, diakses, 28 Desember 2017.

${ }^{15}$ Widyarti. 2005. Strategi Pengelolaan Laboratorium Biologi (Bahan. Pelatihan Manajemen. Laboratorium, Biologi, UNP), h. 1.

${ }^{16}$ Wirjosoemarto.K, dkk. 2004. Teknik Laboratorium. JICA: IMSTEP, h. 40. dalam penelitian ini adalah tempat pembelajaran melalui media praktikum yang dapat menghasilkan pengalaman belajar dimana para siswa dapat berinteraksi dengan berbagai alat dan bahan untuk mengobservasi gejala-gejala yang dapat diamati secara langsung dan membuktikan sendiri sesuatu yang dipelajari. Diantara laboratorium yang dikelola di sekolah adalah laboratorium pendidikan agama Islam (PAI).

Dalam pemahaman istilah, pendidikan agama Islam ialah usaha bimbingan terhadap anak didik agar kelak setelah selesai pendidikannya dapat memahami serta menghayati ajaran-ajaran islam. ${ }^{17}$ Marimba, mendefinisikan Pendidikan Agama Islam sebagai pendidikan jasmani dan rohani didasarkan pada hukum-hukum agama Islam menuju terbentuknya kepribadian utama menurut ukuran Islam. ${ }^{18}$ Menurut Ahmadi, Pendidikan Agama Islam adalah suatu usaha yang lebih dikhususkan untuk mengembangkan fitrah keagamaan subyek didik agar lebih memahami, menghayati dan mengamalkan ajaranajaran Islam. ${ }^{19}$

Pendidikan agama Islam adalah usaha sadar untuk menyiapkan peserta didik dalam meyakini, memahami, menghayati dan mengamalkan agama Islam melalui kegiatan bimbingan, pengajaran dan atau latihan untuk saling menghormati antar internal umat beragama dan antar umat beragama, sehingga tercipta kerukunan masyarakat guna mewujudkan persatuan nasional. ${ }^{20}$

Berdasarkan beberapa definisi tersebut di atas, maka dapat dianalisis bahwa Pendidikan Agama Islam merupakan mata pelajaran atau bidang studi agama Islam yang diselenggarakan di jenjang pendidikan sekolah sebagai salah satu kurikulum wajib bagi peserta didik muslim. Pelajaran ini berusaha untuk memberikan bimbingan terhadap peserta didik menuju terbentuknya kepribadian utama, yaitu

\footnotetext{
${ }^{17}$ Abdul Rahman Saleh. 1976. Didaktik Pendidikan Agama. Jakarta: Bulan Bintang, hh. 19-20.

${ }^{18}$ Marimba, AD. 1989. Pengantar Filsafat Pendidikan Islam. Bandung: Al-Ma'arif, h. 23.

${ }^{19}$ Achmadi. 1992. Islam Sebagai Paradigma Ilmu Pendidikan. Yogyakarta: Aditya Media, h. 20.

${ }^{20}$ Departemen Pendidikan dan Kebudayaan. 1995. Kurikulum Sekolah Menengah Umum Mata Pelajaran Pendidikan Agama Islam. Jakarta: Depdikbud, h.1.
} 
lebih memahami, menghayati dan mengamalkan ajaran agama Islam.

Dalam implementasi pendidikan agama Islam di sekolah agar dapat dikelola dengan sebaik-baiknya, terutama dalam upaya pembentukan sikap, kepribadian, dan keterampilan peserta didik dalam mengamalkan ajaran agamanya, disamping pengetahuan agama peserta didik maka dalam pengelolaannya diperlukan laboratorium PAI di sekolah. Laboratorium PAI mempunyai bebrapa pengertian, yaitu menurut Haidar, laboratorium pendidikan agama Islam merupakan ruangan khusus yang ditata dengan baik dengan bernuansa religius, misalnya musik, sajak, puisi religious dan video yang mengisahkan nuansa keberagamaan. Peserta didik secara bergiliran pada hari-hari yang ditentukan mengikuti pembelajaran di tempat tersebut. ${ }^{21}$ Laboratorium PAI dapat dipahami sebagai suatu bangunan yang di dalamnya dilengkapi dengan peralatan dan bahan-bahan berdasarkan metode keilmuan tertentu untuk melakukan percobaan ilmiah, penelitian, praktek pembelajaran, kegiatan pengujian, dan produksi bahan tertentu dalam hal kaitanya dengan persoalan agama Islam. ${ }^{22}$

Dari analisis teori tersebut di atas maka dapat dipahami bahwa bahwa yang dimaksud laboratorium PAI dalam penelitian ini adalah tempat atau bangunan tertentu yang di dalamnya dilengkapi dengan peralatan dan bahan-bahan PAI berdasarkan metode keilmuan dan ditata agar peserta didik dapat berinteraksi dengan berbagai alat dan bahan untuk mengobservasi gejala-gejala yang dapat diamati secara langsung dan membuktikan sendiri sesuatu yang dipelajari.

Tujuan laboratorium Pendidikan agama Islam menurut Ulin Nuha adalah (1) Mendukung proses pembelajaran PAI dalam menumbuh kembangkan akidah melalui pemberian, pemupukan, dan pengembangan pengetahuan, penghayatan, pengamalan, pembiasaan, serta pengalaman peserta didik

\footnotetext{
${ }^{21}$ Haidar Putra Daulay, dan Nurgayapasa. 2012. Pendidikan Islam Dalam Mencerdaskan Bangsa. Jakarta: Rineka Cipta, h. 42.

${ }^{22}$ Ratna Sundari. Evaluasi Pemanfaatan Laboratorium Pembelajaran Biologi di Madrasah Aliyah Negeri se-Kabupaten Sleman, dalam http://journal.uny.ac.id/index.php/jpep/article/download/ 1427/1215, diakses 28 Desember 2017.
}

tentang agama Islam sehingga menjadi manusia muslim yang terus berkembang keimanan dan ketaqwaanya kepada Allah SWT; dan (2) Menyediakan alat peraga dan laboratorium dalam rangka memperkuat aqidah, berkahlak mulia, memperluas pengetahuan agama dan rajin beribadah. ${ }^{23}$

Laboratorium PAI ini berfungsi untuk menunjang kegiatan-kegiatan dalam pembelajaran PAI secara efektif, diantaranya melalui penggunaan peralatan Micro Teaching dan ruang belajar untuk praktek keagamaan. Secara umum fungsi semua laboratorium PAI adalah: (a) sebagai tempat praktek keagamaan, (b) sebagai tempat penunjang kegiatan kelas. Dengan adanya kegiatan pembalajaran di laboratorium, siswa dapat mengamati gejalagejala yang terjadi dalam percobaan secara langsung dan tidak hanya belajar menurut teori-teori yang ada, (c) sebagai tempat display/pameran. Laboratorium PAI juga dapat digunakan sebagai tempat pameran atau display dari hasil-hasil percobaan atau penelitian yang telah dilakukan, agar memberi gambaran lebih dan dapat memotivasi untuk penelitian atau percobaan yang lebih baik, dan (d) sebagai museum kecil.

Laboratorium PAI di sekolah yang dibutuhkan adalah laboratorium PAI yang terstandar sesuai dengan Keputusan Menteri Agama Nomor 211 Tahun 2011 tentang Pedoman Pengembangan Standar Nasional Pendidikan Agama Islam pada Sekolah. Lahirnya peraturan tertesbut didasarkan pada Peraturan Pemerintah Nomor 19 Tahun 2005 tentang Standar Nasional Pendidikan (SNP) yang berfungsi sebagai dasar dalam perencanaan, pelaksanaan, dan pengawasan pendidikan dalam rangka mewujudkan pendidikan nasional yang bermutu. SNP merupakan kriteria minimal untuk menjamin mutu pendidikan nasional dalam rangka mencerdaskan kehidupan bangsa dan membentuk watak serta karakter bangsa yang bermartabat. Selanjutnya dalam Peraturan Pemerintah Nomor 55 Tahun 2007, dinyatakan bahwa pengelolaan pendidikan agama dan pendidikan keagamaan

${ }^{23}$ Ulin Nuha. 2013. Standar laboratorium Pendidikan Agama Islam pada Sekolah. Bab I", dalam http://ulinnuhatuban. blogspot.com/2013/08/standarlaboratorium-pendidikan-agama, diakses 28 Desember 2017. 
berada pada Kementerian Agama RI. Sebagai pengelola pendidikan agama, Kementerian Agama berkewajiban menjamin mutu Pendidikan Agama di sekolah. ${ }^{24}$

Dalam rangka penyelenggaraan Pendidikan Agama Islam (PAI) yang bermutu dan sesuai dengan kebutuhan masyarakat, maka Kementerian Agama perlu membuat $\mathrm{Ke}$ putusan Menteri Agama, yaitu Keputusan Menteri Agama Nomor 211 Tahun 2011 tentang Pedoman Pengembangan Standar Nasional Pendidikan Agama Islam pada Sekolah. Pada Bab VIII tentang Pedoman Pengemebangan Standar Sarana Prasarana Pendidikan Agama Islam pada SMA/SMK tentang Laboratorium PAI di Sekolah. Dalam peraturan tersebut, telah dijelaskan secara rinci standar minimal laboratorium PAI di SMA. Adapun standar laboratorium PAI di SMA/SMK tersebut adalah sebagai berikut: ${ }^{25}$ Fungsi laboratorium Pendidikan Agama Islam di Sekolah berfungsi: (1) Mendukung proses pembelajaran PAI dalam meningkatkan keimanan melalui pemberian, pemupukan, dan pengembangan pengetahuan, penghayatan, pengamalan, pembiasaan, serta pengalaman peserta didik tentang Agama Islam sehingga menjadi manusia muslim yang terus meningkat keimanan dan ketakwaannya kepada Allah SWT; (2) Menyediakan alat peraga dan laboratorium untuk melengkapi metode dan strategi penguatan akidah, pembiasaan akhlak mulia, dan kualitas beribadah; dan (3) Memberi keterampilan dan pelatihan mengajar bagi GPAI dengan media Teknologi informasi dan komunikasi (TIK).

Dalam ketentuan laboratorium PAI, sekolah harus menyediakan prasarana Laboratorium Pendidikan Agama Islam yang berfungsi sebagai tempat peserta didik untuk mencari informasi digital tentang Islam dan melaksanakan praktek keterampilan keagamaan, dan kegiatan lainnya yang mendukung pembelajaran PAI, baik berbentuk kegiatan intra kurikuler maupun ekstrakurikuler. Prasarana Laboratorium Pendidikan Agama Islam merupakan bangunan/ruangan yang disediakan khusus untuk keperluan tersebut di atas. Luas

\footnotetext{
${ }^{24}$ PP. Nomor 55 Tahun 2007, Op. cit.

${ }^{25}$ Keputusan Menteri Agama Nomor 211 Tahun 2011 tentang Pedoman Pengembangan Standar Nasional Pendidikan Agama Islam pada Sekolah.
}

minimum bangunan prasarana ibadah adalah $56 \mathrm{~m}^{2}(8 \times 7 \mathrm{~m})$, kedap suara, beralaskan karpet, daya listrik minimal 900 watt, dan dilengkapi sarana Laboratorium PAI. Sarana laboratorium PAI meliputi perabot, peralatan pendidikan, media pendidikan, perlengkapan prabot, perlengkapan seni Islami, dan perlengkapan lainnya.

Prasarana Laboratorium Pendidikan Agama Islam dan sarana yang ada di sekolah dikelola oleh GPAI, dengan melibatkan unsurunsur lain yang ditetapkan oleh manajemen tertinggi SMA/SMK. Dalam menjalankan tugas pengelolaan prasarana Laboratorium Pendidikan Agama Islam, Guru Pendidikan Agama Islam bertanggungjawab kepada kepala sekolah. Sekolah harus melakukan pemeliharaan sarana dan prasarana Laboratorium Pendidikan Agama Islam dengan menganggarkan biaya pemeliharaan setiap tahun anggaran dan menyediakan tenaga khusus. Adapun pemanfaatan laboratorium PAI sebagai: 1) Penunjang kegiatan pembelajaran PAI; 2) Sarana visualisasi konsep-konsep agama Islam; 3) Sarana praktik pembelajaran agama Islam; 4) Model imitasi pelaksanaan ibadah; dan 5) Pengolahan bahan dakwah

Dengan adanya laboratorium PAI di sekolah diharapkan mutu pembelajaran PAI meningkat. Diantara mutu pembelajaran PAI dapat dilihat melalui tingkat prestasi belajar PAI siswa di sekolah. Ketika tingkat prestasi PAI tidak selalu menunjukan tinggi, sesungguhnya dapat dilihat dari kendalakendalanya, sebagai bahan refleksi bagi perbaikan mutu pengembangan laboratorium PAI dalam peningkatan mutu pembelajaran PAI di sekolah.

\section{METODE PENELITIAN}

Penelitian ini menggunakan metode kualitatif. Penelitian ini bersifat kasuistik (case study). Pada kasus ini peneliti melakukan analias terhadap laboratorium PAI di sekolah dengan cara melakukan pemilihan narasumber dengan mengedepankan narasumber yang terkait langsung dengan penelitian yaitu Kepala Sekolah, Wakil Kepala Sekolah bagian sarana prasarana, Guru Pendidikan Agama Islam, Tenaga laboran dan Siswa.

Penelitian dilaksanakan pada bulan Juli hingga Desember 2016. Lokasi penelitian 
adalah SMAN 3 Bandung. SMAN 3 Bandung merupakan SMAN yang maju dalam pengelolaan pendidikan agama Islam dikarenakan telah memiliki laboratorium PAI, dengan pemanfaatan yang efektif.

Pengumpulan data dilakukan melalui wawancara mendalam (deep interview) kepada informan seperti guru agama, laboran dan kepala sekolah. Observasi dilakukan terhadap kegiatan laboratorium pendidikan agama. Sementara telaah dokumen dilakukan terhadap benda-benda tertulis yang ada kaitan dengan penelitian. Analisis data dilakukan secara simultan yang dilakukan bersamaan dengan proses pengumpulan data dengan alur tahapan; pengumpulan data, reduksi data, penyajian data, kesimpulan atau verifikasi.

\section{HASIL DAN PEMBAHASAN}

\section{Profil Laboratorium PAI}

Lahirnya laboratorium PAI SMAN 3 Bandung dilatarbelakangi oleh adanya pandangan bahwa agama memiliki peran penting menjadi pemandu dalam upaya mewujudkan suatu kehidupan yang bermakna, damai dan bermartabat dalam kehidupan umat manusia. Menyadari betapa pentingnya peran agama bagi kehidupan umat manusia maka internalisasi nilai-nilai agama dalam kehidupan setiap pribadi menjadi sebuah keniscayaan, yang ditempuh melalui pendidikan baik pendidikan di lingkungan keluarga, sekolah maupun masyarakat.

Pendidikan agama dimaksud untuk peningkatan potensi spiritual dan membetuk peserta didik agar menjadi manusia yang beriman dan bertakwa kepada Tuhan Yang Maha Esa dan berakhlak mulia. Akhlak mulia mencakup etika, budi pekerti, dan moral sebagai perwujudan dari pendidikan agama. Peningkatan potensi spiritual mencakup pengamalan, pemahaman, dan penanaman nilainilai keagamaan, serta pengamalan nilai-nilai tersebut dalam kehidupan individual ataupun kolektif kemasyarakatan. Peningkatan potensi spiritual tersebut pada akhirnya bertujuan pada optimalisasi berbagai potensi yang dimiliki manusia yang aktualisasinya mencerminkan harkat dan martabatnya sebagai makhluk Tuhan.

Pendidikan Agama Islam diberikan dengan mengikuti tuntunan bahwa agama diajarkan kepada manusia dengan visi untuk mewujudkan manusia yang bertakwa kepada Allah SWT dan berakhlak mulia, serta bertujuan untuk menghasilkan manusia yang jujur, adil, berbudi pekerti, etis, saling menghargai, disiplin, harmonis dan produktif, baik personal maupun sosial. Tuntutan visi ini mendorong dikembangkannya standar laboratorium sesuai dengan jenjang Pendidikan yang secara nasional ditandai dengan ciri-ciri: (1) lebih menitik beratkan pencapaian pemanfaatan dan pemberdayaan laboratorium Pendidikan Agama Islam; dan (2) mengakomodasikan keragaman kebutuhan dan sumber daya pendidikan yang tersedia.

Pendidikan Agama Islam diharapkan menghasilkan manusia yang selalu berupaya menyempurnakan iman, takwa, dan akhlak, serta aktif membangun peradaban dan keharmonisan kehidupan, khususnya dalam memajukan peradaban bangsa yang bermartabat. Manusia seperti itu diharapkan tangguh dalam menghadapi tantangan, hambatan, dan perubahan yang muncul dalam pergaulan masyarakat baik dalam lingkup lokal, nasional, regional maupun global. Pendidik diharapkan dapat mengembangkan penggunaan laboratorium untuk mendukung pembelajaran Pendidikan Agama Islam. Peran semua unsur sekolah, orang tua peserta didik dan masyarakat sangat penting dalam mendukung keberhasilan pencapaian tujuan Pendidikan Agama Islam.

Dengan dasar pemikiran tersebut di atas laboratorium PAI di SMAN 3 Bandung lahir. Di samping itu bermula ketika kepala SMAN 3 mengikuti seleksi kepala sekolah peduli pendidikan agama Islam, dan masuk final lalu seleksi tahap akhir dilaksanakan di sekolah maka sebelumnya dibicarakan dengan guruguru PAI, mengenai strategi dan rencana apa yang harus dipersiapkan, maka muncullah ide yang disampaikan bahwa keberadaan sebuah laboratorium PAI akan mempunyai nilai tambah yang jauh lebih berharga dari fasilitas lain, karena laboratorium PAI akan menjadi sebuah tuntutan kebutuhan. Atas dasar pemikiran tersebut di atas dan hasil perbincangan tentang pentingnya laboratorium PAI inilah kemudian mereka sepakat untuk mendirikan laboratorium PAI SMAN 3 Banding. Untuk itu, kepala sekolah dan pihak 
terkait khususnya guru pendidikan agma Islam mempersiapkan segala sesuatunya agar laboratorium PAI berdiri di SMAN 3 Bandung. Adapun landasan operasional laboratorium PAI di SMAN 3 Bandung adalah: (1) Visi SMAN 3 Bandung, yaitu "Terwujudnya Sekolah Bertaraf Internasional yang Unggul Dalam Bidang IPTEK Berwawasan Kebangsaan dan Berbudaya Lingkungan Berdasarkan Imtaq"; (2) Misi SMA N 3 Bandung poin 5, yaitu "Mengembangkan potensi kecerdasan intelektual, emosional, dan spiritual melalui pendidikan akhlak dan kepribadian untuk peningkatan manajemen mutu"; (3) kebijakan mutu SMAN 3 Bandung poin 2, yakni "Meningkatkan Mutu Peserta Didik";

Kompetensi SMA N 3 Bandung poin 1, yaitu "Kompetensi Iman dan Taqwa"; dan Motto SMA N 3 Bandung, yaitu "Knowledge is Power but Character is More”.

Visi: Menjadi Sekolah berbasis Riset terdepan dalam pembentukan Karakter unggul dalam Imtaq dan Iptek. Misi: yaitu: 1) membangun SDM yang unggul dalam Imtaq dan Iptek sesuai dengan dinamika globalisasi; 2) mewujudkan pendidik dan tenaga kependidikan dan peserta didik yang memiliki integritas; 3) mewujudkan lulusan yang berkarakter dan berwawasan kebangsaan, serta peduli terhadap lingkungan hidup; 4) mengembangan potensi kecerdasan intelektual, emosional dan spiritual guna memberikan solusi terhadap dinamika permasalahan bangsa dan Negara; dan 5) menjalin kemitraan dengan Stakeholders (pemangku kepentingan) melalui peningkatan pelayanan prima, transparan dan akuntabel guna membangun komunikasi yang harmonis dengan mitra kerja secara formal dan non formal. Adapun Tujuan Lab PAI: Laboratorium Pendidikan Agama Islam di Sekolah Menengah Atas Negeri 3 Bandung bertujuan untuk: 1) mendukung proses pembelajaran PAI dalam menumbuh kembangkan akidah melalui pemberian, pemupukan, dan pengembangan pengetahuan, penghayatan, pengamalan, pembiasaan, serta pengalaman peserta didik tentang Agama Islam sehingga menjadi manusia muslim yang terus meningkat keimanan dan ketakwaannya kepada Allah SWT; 2) Menyediakan alat peraga dan laboratorium dalam rangka memperkuat akidah, berakhlak mulia, memperluas pengetahuan agama, dan rajin beribadah; 3) Memberi keterampilan dan pelatihan mengajar bagi guru PAI dengan media Teknologi Informasi dan Komunikasi (TIK); 4) Memanfaatkan media (TIK) secara maksimal; 5) membuat media pembelajaran agama yang menarik; 6) Mengevaluasi proses belajar mengajar di sekolah dan mengembangkannya dengan media TIK; 7) Sarana laboratorium PAI berfungsi sebagai alat bantu mendukung kegiatan praktek pendidikan agama Islam; dan 8) menciptakan pembelajaran menjadi menyenangkan.

Struktur Organisasi Lab PAI SMAN 3 Bandung, meliputi Penasihat: Kepala Sekolah (Drs.H.Encang Iskandar, M.Pd), Penanggung Jawab: Guru Pendidikan Agama Islam, terdiri atas H.Dadang Suhaedar, M.Ag., Nunung Nurhayati,M.Ag., dan Diden Rosenda, M.Ag., Koordinator PAI : Diden Rosenda, M.Ag., Laboran : Neng Fitriani, S.PdI., dan Pembantu : Rohis Kelas

Sebagaimana laboratorium pada umumnya, laboratorium Pendidikan Agama Islam SMAN 3 Bandung pun berusaha untuk difungsikan sebagai tempat mencari ilmu yang menyenangkan namun tetap berdasarkan ruang lingkup Pendidikan Agama Islam. Ruang lingkup Laboratorium Pendidikan Agama Islam di SMAN 3 Bandung meliputi aspekaspek; Al-Qur'an dan Hadits, Aqidah dan Akhlak, Fiqih, dan Tarikh (Sejarah Islam) dan Kebudayaan Islam.

\section{Agenda Kegiatan}

Selama ini laboratorium PAI SMAN 3 Bandung digunakan untuk melaksanakan pembelajaran PAI dengan media teknologi informasi dan komunikasi (TIK) di sekolah dan melaksanakan praktek pembelajaran PAI dengan media pembelajaran. Agenda kegiatan ini berisi mengenai pengaturan jadwal pemakaian laboratorium PAI itu sendiri oleh guru Pendidikan Agama Islam dengan tujuan supaya tidak ada rencana pemakaian secara bersama dalam arti kata dalam waktu yang sama terdapat dua orang pemakai, hal itu perlu diatur karena akan menyulitkan dalam penggunaan laboratorium tersebut.

Agenda Kegiatan Lab PAI SMAN 3 Bandung, meliputi hari: Senin, kegiatan 
laboratorium PAI dilakukan oleh H.Dadang Suhaedar, M.Ag (GPAI) dengan tema kegiatan pembelajaran agama tentang haji, zakat, pengurusan jenazah dan tarikh; Selasa, kegiatan laboratorium PAI dilakukan oleh Diden Rosenda, M.Ag (GPAI) dengan tema kegiatan pembelajaran agama tentang munakahat, mawaris, dan tarikh; Rabu, kegiatan laboratorium PAI dilakukan oleh Nunung Nurhayati, M.Ag (GPAI) dengan tema kegiatan pembelajaran agama tentang pengurusan jenazah, tarikh, munakahat dan mawaris; Kamis, kegiatan laboratorium PAI dilakukan oleh H.Dadang Suhaedar, M.Ag (GPAI) dengan tema kegiatan pembelajaran agama tentang haji, dan pengurusan jenazah; Jumat, kegiatan laboratorium PAI dilakukan oleh Diden Rosenda, M.Ag (GPAI) dengan tema kegiatan pembelajaran agama tentang haji, zakat, dan tarikh; dan sabtu, kegiatan laboratorium PAI dilakukan oleh Diden Rosenda, M.Ag (GPAI) dengan tema kegiatan pembelajaran agama tentang haji, zakat, tarikh, mawaris dan munakahat.

\section{Perlengkapan Sarana/Barang}

Sebagaimana layaknya sebuah laboratorium, tentunya banyak sarana yang diperlukan untuk kelengkapan laboratorium Pendidikan Agama Islam yang tentunya akan memerlukan tidak sedikit biaya. Tapi untuk ukuran SMA Negeri 3 Bandung sudah sangatlah mendesak kebutuhan akan sebuah laboratorium Pendidikan Agama Islam, karena lab PAI ini merupakan program unggulan Kementrian Agama, sehingga kantor Kementrian Agama Pusat menyalurkan dana ke sekolah-sekolah dari mulai tingkat TK sampai tingkat SMA. Untuk keperluan penyelenggaraan lab. PAI, SMA Negeri 3 tidak termasuk pada sekolah yang mendapatkan dana tersebut, maka dengan menggunakan dana sendiri harus mampu menyelenggarakan lab.tersebut.

Untuk perlengkapan Lab PAI SMAN 3 Bandung yang dimiliki yaitu: (1) peralatan pendidikan, meliputi Gambar Simulasi Pelaksanaan Ibadah Haji \& bingkai, Gambar Ka'bah \& bingkai, Gambar Pelaksanaan Wudlu, Gambar Pelaksanaan Salat \& bingkai, Gambar Simulasi Pengurusan Jenazah, Gambar Simulasi Zakat, Gambar simulasi wakaf, dan Penunjuk Waktu Salat; (2) media pendidikan, meliputi CD. Pelaksanaan Salat, CD. Pelaksanaan Wudlu, CD. Ibadah Haji, CD.lain yang relevan dengan bahan ajar, CD. Penciptaan Alam Semesta Harun Yahya, Kit Al-Qur'an, Maket Ka'bah, Gambar Peragaan Wudlu, Gambar Peragaan Salat Dua Dimensi atau Tiga Demensi, Kain Ihram, Kompas Penentu Arah Kiblat, Globe dan Peta NegaraNegara Islam dan Negara yang Mayoritas penduduknya beragama Islam;

Perlengkapan Lain, meliputi Buku Inventaris, Alat Kebersihan (tempat sampah, sapu, lap pel, sapu lidi, kemoceng, pengki, lap tangan, mangkok air), Kotak Kontak, Jam Dinding, Kain Gorden, Ceiling Fan, Karpet Lantai, Alat peraga jenazah, Peralatan kaligrafi, dan Lemari/Rak.

Terkait alat peraga pendidikan agama Islam, yang dimiliki meliputi: (1) perabot, berupa satu buah lemari/rak untuk menyimpan seluruh alat peraga, dengan kondisi tertutup dan dapat dikunci; (2) Peragaan pendidikan dan seni, berupa satu set model tubuh manusia untuk praktek memandikan, mengkafani, mensalatkan jenazah, dapat diamati dengan mudah oleh seluruh peserta didik, dan dapat dibongkar pasang, peralatan rebana satu set, peralatan marawis, peralatan khot dan kaligrafi; dan (3) perlengkapan lain, berupa buku inventaris, alat kebersihan dan jam dinding.

\section{Kebijakan Pengelolaan Laboratorium PAI}

Penetapan kebijakan pengelolaan laboratorium PAI di SMAN 3 Bandung tidak lepas didasarkan pada peraturan perundangundangan yang berlaku. Peraturan perundangundangan yang menjadi dasar pedoman kebijakan pengelolaan laboratorium PAI di SMAN 3 Bandung, antara lain Undang-undang Sisdiknas No 20 tahun 2003, yang menyebutkan tujuan pendidikan nasional adalah: "berkembangnya potensi peserta didik, agar menjadi manusia yang beriman dan bertakwa kepada Tuhan YME, berakhlak mulia, sehat, berilmu, cakap, kreatif, mandiri, dan menjadi warga negara yang demokratis san bertanggung jawab";

Peraturan Pemerintah Nomor 19 Tahun 2005 tentang Standar Nasional Pendidikan (SNP) yang berfungsi sebagai dasar dalam 
perencanaan, pelaksanaan, dan pengawasan pendidikan dalam rangka mewujudkan pendidikan nasional yang bermutu. SNP merupakan kriteria minimal untuk menjamin mutu pendidikan nasional dalam rangka mencerdaskan kehidupan bangsa dan membentuk watak serta karakter bangsa yang bermartabat. Selanjutnya dalam Peraturan Pemerintah Nomor 55 Tahun 2007, dinyatakan bahwa pengelolaan pendidikan agama dan pendidikan keagamaan berada pada Kementerian Agama RI. Sebagai pengelola pendidikan agama, Kementerian Agama berkewajiban menjamin mutu Pendidikan Agama di sekolah.

Instruksi Presiden Republik Indonesia Nomor 1 Tahun 2010 tentang Percepatan Pelaksanaan Prioritas Pembangunan Nasional Tahun 2010 yang mengamanatkan program penguatan metodologi dan kurikulum dengan cara menyempurnakan kurikulum dan metode pembelajaran aktif berdasarkan nilai-nilai budaya bangsa untuk membentuk daya saing dan karakter bangsa, dalam rangka penyelenggaraan Pendidikan Agama Islam (PAI) yang bermutu dan sesuai dengan kebutuhan masyarakat, maka Kementerian Agama perlu membuat Keputusan Menteri Agama, yaitu Keputusan Menteri Agama Nomor 211 Tahun 2011 tentang Pedoman Pengembangan Standar Nasional Pendidikan Agama Islam pada Sekolah. Pada Bab VIII tentang Pedoman Pengemebangan Standar Sarana Prasarana Pendidikan Agama Islam pada SMA/SMK tentang Laboratorium PAI di Sekolah.

Proses penetapan kebijakan yang dilakukan SMAN 3 Bandung terhadap laboratorium PAI, menurut kordinator laboratorium PAI SMAN 3 Bandung, adalah melalui musyawarah komite sekolah, kepala sekolah, dan guru pendidikan agama Islam, yang memandang perlunya mendirikan laboratorium PAI di SMAN 3 Bandung. Yaitu, keberadaan sebuah laboratorium PAI di sekolah akan mempunyai nilai tambah yang jauh lebih berharga dari fasilitas lain, karena laboratorium PAI akan menjadi sebuah tuntutan kebutuhan. Dari perbincangan tentang pentingnya laboratorium PAI inilah kemudian kepala sekolah mempersiapkan segala sesuatunya agar laboratorium PAI berdiri di SMAN 3 Bandung.

Proses penetapan kebijakan yang dilakukan terhadap pengelolaan laboratorium PAI di SMAN 3 Bandung yaitu, langkah awal adalah mengadakan musyawarah dan persetujuan kepala sekolah dengan pihak komite sekolah dan guru PAI, yang dipicu dari lomba perhatian dan peduli kepala sekolah terhadap pendidikan agama di sekolah. Selanjutnya kepala sekoalah mendorong guru agama mencari informasi atau bekerjasama dengan pihak-pihak lain yang berkaitan dengan pengelolaan laboratorium PAI di Sekolah.

Dasar penetapan kebijakan dilakukan terhadap laboratorium PAI di sekolah juga karena implementasi dari keberhasilah kepala sekolah sebagai kepala sekolah yang peduli kepada pendidikan agama Islam, dilanjutkan dan disepakati oleh kepala sekolah penggantinya. Adapun unsur-unsur yang terlibat dalam pengelolaan laboratorium PAI di sekolah adalah kepala sekolah, wakil manajemen mutu, wakil kepala sekolah, guruguru PAI, stap TU dan caraka (utusan). Dan orang yang ditunjuk sebagai pengelola laboratorium PAI di SMAN 3 Bandung adalah guru pendidikan agama Islam, terutama Ibu Diden Rosenda M.Pd.

\section{Kelengkapan Laboratorium PAI}

Untuk kelengkapan laboratorium PAI, SMAN 3 Bandung telah menyediakan prasarana laboratorium Pendidikan Agama Islam yang berfungsi sebagai tempat peserta didik untuk mencari informasi digital tentang Islam dan melaksanakan praktek keterampilan keagamaan, dan kegiatan lainnya yang mendukung pembelajaran PAI, baik berbentuk kegiatan intra kurikuler maupun ekstrakurikuler. Untuk Prasarana Laboratorium PAI yang merupakan bangunan/ruangan yang disediakan khusus untuk keperluan tersebut di atas, luas bangunan prasarananya telah mencapai luas $56 \mathrm{~m} 2(8 \mathrm{mx} 7 \mathrm{~m})$, beralaskan karpet, daya listrik minimal 900 watt, kekurangannya belum kedap suara.

Untuk kelengkapan sarana laboratorium PAI di SMAN 3 Bandung dilihat dari kelengkapan barang yang harus ada di laboratorium PAI sebagaimana PMA no 211 tahun 2011, hampir tersedia, kecuali AC dan 
wastapel yang belum ada. Keadaan perlengkapan lab PAI SMAN 3 Bandung yang sudah sesuai dengan tuntutan peraturan Menteri agama tentang standar laboratorium PAI, yaitu: (1) peralatan pendidikan, meliputi Gambar Simulasi Pelaksanaan Ibadah Haji \& bingkai, Gambar Ka'bah \& bingkai, Gambar Pelaksanaan Wudlu, Gambar Pelaksanaan Salat \& bingkai, Gambar Simulasi Pengurusan Jenazah, Gambar Simulasi Zakat, Gambar simulasi wakaf, dan Penunjuk Waktu Salat; (2) media pendidikan, meliputi CD. Pelaksanaan Salat, CD. Pelaksanaan Wudlu, CD. Ibadah Haji, CD.lain yang relevan dengan bahan ajar, CD. Penciptaan Alam Semesta Harun Yahya, Kit Al-Qur'an, Maket Ka'bah, Gambar Peragaan Wudlu, Gambar Peragaan Salat Dua Dimensi atau Tiga Demensi, Kain Ihram, Kompas Penentu Arah Kiblat, Globe dan Peta Negara-Negara Islam dan Negara yang Mayoritas penduduknya beragama Islam; (3) Perlengkapan Lain, meliputi Buku Inventaris, Alat Kebersihan (tempat sampah, sapu, lap pel, sapu lidi, kemoceng, pengki, lap tangan, mangkok air), Kotak Kontak, Jam Dinding, Kain Gorden, Ceiling Fan, Karpet Lantai, Alat peraga jenazah, Peralatan kaligrafi, dan Lemari/Rak. Kecuali AC dan wastapel yang belum tersedia.

Untuk alat peraga pendidikan agama Islam, yang telah tersedia, meliputi: (1) perabot, berupa satu buah lemari/rak untuk menyimpan seluruh alat peraga, dengan kondisi tertutup dan dapat dikunci; (2) Peragaan pendidikan dan seni, berupa satu set model tubuh manusia untuk praktek memandikan, mengkafani, mensalatkan jenazah, dapat diamati dengan mudah oleh seluruh peserta didik, dan dapat dibongkar pasang, peralatan rebana satu set, peralatan marawis, peralatan khot dan kaligrafi; dan (3) perlengkapan lain, berupa buku inventaris, alat kebersihan dan jam dinding.

Dengan keadaan sarana laboratorium PAI di SMAN 3 Bandung sebagaimana tersebut di atas, dapat dipahami bahwa sarana laboratorium PAI di SMAN 3 Bandung telah mencapai standar yang dikehendaki kesesuaiannya dengan PMA Nomor 211 tahun 2011. Sarana yang belum tersedia adalah AC dan Wastapel saja.

\section{Pemanfaatan Laboratorium PAI}

Khusus pembelajaran PAI di SMAN 3 Bandung dilakukan dengan cara moving kelas, yaitu pembelajaran PAI yang dilaksanakan di laboratorium PAI. Hal ini dilakukan agar pembelajaran PAI dapat dilakukan lebih efektif dan memadai. Dari hasil wawancara dengan salah satu guru PAI menyatakan bahwa proses pembelajaran PAI sebagaimana proses pembelajaran PAI di kelas dilaksanakan di laboratorium PAI. Namun demikian pembelajaran PAI yang dilaksanakan di laboratorium PAI memiliki ketentuanketentuan yang harus atau tidak boleh dilakukan siswa, misalnya harus membuka sepatu, tidak boleh membawa makanan dsb. Model pendekatan yang dipraktekkan guru dalam pembelajaran PAI di laboratorium PAI yaitu bermain peran dan demonstrasi. Dengan model pendekatan ini peserta didik merespon positif, dan merasa ada suasana lain yang berbeda dengan model pendekatan pembelajaran di kelas. Bila dilihat dari partisipasi peserta didik dalam pembelajaran PAI di laboratorium PAI di sekolah, maka peserta didik sangat antusias mengikuti pembelajaran di laboratorium PAI, dan ini juga sebagai wujud partisipasi peserta didik dalam pembelajaran PAI yang dilaksanakan di laboratorium PAI.

Untuk mengoptimalkan pelaksanaan pembelajaran PAI di laboratorium, GPAI memepersiapkan pembelajaran secara matang, dan selama ini mereka merasa tidak perlu mengundang tenaga laboran luar sekolah untuk mendukung pembelajaran PAI di laboratorium PAI di sekolah. Alasannya sederhana yaitu belum diperlukan, apa yang bisa atau dikerjakan oleh seorang laboran di laboratorium PAI, masih bisa diatasi oleh GPAI.

Bahan ajar/referensi literatur yang digunakan dalam pembelajaran PAI di laboratorium PAI di SMAN 3 Bandung diantaranya meliputi berbagai tafsir sebagai alat pembelajaran yang membantu memperkaya referensi. Metode pembelajaran yang sering digunakan dalam pembelajaran PAI di laboratorium PAI meliputi metode pembelajaran praktik, demonstrasi, dan terstimoni. Alat bantu pembelajaran yang digunakan dalam pembelajaran PAI di laboratorium PAI adalah disesuaiakan dengan materi. Jika materi 
itu bab haji maka yang dipakai properti haji, jika materi itu bab jenazah maka yang dipakai property jenazah.

System evaluasi pembelajaran PAI di laboratorium PAI di sekolah adalah disesuaikan dengan materi pembelajaran, seperti model evaluasi praktik dan lisan. Manfaat hasil evaluasi terhadap posisi dan kedudukan PAI di sekolah adalah sangat efektif. Indikator/ kriteria utama penilaian dalam evaluasi pembelajaran PAI di laboratorium PAI adalah siswa bisa mempraktikkan sesuai materi.

Laboratorium PAI yang didalamnya dilengkapi dengan sarana-sarana pembelajaran, maka hal ini dapat difungsikan sebagai upaya pemanfaatan sarana visualisasi konsep-konsep PAI. Visualisasi konsep-konsep PAI dalam bentuk pembelajaran yang bersifat kognitif, lebih banyak disampaikan melalui multi media, dengan peralatan laptop dan infocus: seperti visualisasi konsep wudlu, salat, haji, penciptaan alam semesta dan lain sebagainya yang relevan dengan bahan ajar.

Pemanfaaatan laboratorium PAI diantaranya digunakan untuk peraktek pembelajaran PAI yang dilengkapi dengan media pembelajaran. Yaitu melalui simulasisimulasi yang dilakukan di laboratorium PAI, antara lain; simulasi zakat, simulasi pelaksanaan ibadah haji, simulasi pengurusan jenazah, salat jenazah, dan simulasi wakaf. Model imitasi pelaksanaan ibadah yang terdapat dalam laboratortium pendidikan agama Islam, misalnya meliputi; gambar ka'bah, gambar penunjuk waktu salat, gambar pelaksanaan wudlu, dan gambar pelaksanaan salat.

Diantara pembelajaran PAI yang dilaksanakan di lab PAI di SMAN 3 adalah materi atau bahan dakwah. Bahan dakwah diolah dalam bentuk pembelajaran yang harus dikuasai oleh peserta didik. Dakwah sendiri berarti memanggil, menyeru, mengajak akan sesuatu hal, yakni kegiatan mengajak orang lain. Bisa bersifat dua arah. Dalam berdakwah minimal ada dua cara, yaitu dakwah dengan lisan : (da'wah billisān) dan dakwah dengan perbuatan (da'wah bilhāl). Dakwah billisan artinya dakwah yang dilakukan dengan berkata-kata, ceramah, $t a b l^{3} g$ akbar, dan sebagainya. Dakwah bilhal artinya dakwah yang dilakukan dengan berbuat, seperti menyantuni fakir miskin, yatim piatu, menyumbang untuk fasilitas sosial, dan sebagainya.

Pengolahan bahan dakwah dapat dilakukan melalui pendekatan Scientific learning, melalui metode Tanya Jawab, Diskusi, Simulasi, dan Dril. Media VCD Dakwah, alat LCD, Laptop, sumber: Buku teks pegangan siswa PAI dan Budi Pekerti Kelas XI SMA hal 52-66, CD, VCD, MP3 dan media lainnya yang relevan, dan refrensi lain yang relevan.

Tahapan kegiatan meliputi kegiatan mengamati, menanya, mengekplorasi/berdiskusi, menyusun bahan presentasi/asosiasi dan mengkomunikasikan sampai membuat kesimpulan tentang materi serta penilaian. Bagian terpenting dari pengolahan bahan dakwah adalah melakukan refleksi yaitu menampilkan kemampuan menerapkan ketentuan dan tata cara pelaksanaan dakwah di masyarakat, dan menunjukkan sikap menghargai dan menghormati pelaksanaan dakwah di masyarakat.

\section{Penilaian Peserta Didik tentang Pembelajaran di Lab PAI}

Kebermanfaatan laboratorium PAI dalam meningkatkan mutu pembelajaran PAI di sekolah, menurut laporan GPAI dan peserta didik sangat merasakan manfaat dari laboratorium PAI dalam pembelajaran, dan ada suasana lain yang berbeda dengan pembelajaran di kelas. Penilaian peserta didik tentang pengelolaan laboratorium PAI di SMAN 3 Bandung melibatkan sampel sebanyak 33 orang. Pembahasannya, untuk memaknai data kuantitatif menyangkut kategori, nilai angka/prosentase dan interprestasi data penilaian peserta didik tentang pengelolaan laboratorium PAI di SMAN 3 Bandung tersebut, diperlukan acuan kategori penilaian atau pendapat tertentu. Kategori untuk menilai pendapat seseorang terhadap aspek penilaian tertentu, peneliti menggunakan kategori penilaian dari PermenPAN dan Reformasi No.

13 Tahun 2010, yaitu nilai angka/prosentase >85-100 dengan interpretasi Memuaskan, $>75-85$ Sangat Baik, >65-75 Baik, >50-65 Cukup Baik, >30-50 Agak Kurang, dan $>0-30$ Kurang.

Penilaian peserta didik tentang pengelolaan laboratorium PAI di SMAN 3 
Bandung, bahwa ketika laboratorium menjadi penunjang kegiatan pembelajaran PAI, menurut penilaian peserta didik terdapat lima pernyataan yang dinilai sangat tinggi oleh hampir semua peserta didik dengan kategori memuaskan, yaitu pada pernyataan peserta didik 33 (100\%) lebih menyukai pembelajaran PAI di laboratorium daripada di kelas, 32 $(96,96)$ peserta didik merasa ada perbedaan pembelajaran di laboratorium PAI dengan pembelajaran di kelas, 32 (96,96\%) peserta didik merasa bahwa pembelajaran di laboratorium PAI lebih menyenangkan, pembelajaran di laboratorium PAI terasa lebih mudah memahami materi, dan 32 (96,96\%) peserta didik merasa bahwa pembelajaran di laboratorium PAI mudah menyesuaikan diri dengan cara belajar sekarang.

Terdapat lima pernyataan yang dinilai oleh sebagian besar peserta didik dengan kategori sangat baik, yaitu pada pernyataan bahwa $27(81,81 \%)$ peserta didik tentang pembelajaran di laboratorium PAI lebih bersemangat belajar, $26(78,78 \%)$ peserta didik merasa pembelajaran di laboratorium PAI menjadi lebih mampu menyampaikan pendapat, $28(84,84 \%)$ peserta didik merasa pembelajaran di laboratorium PAI menjadi lebih terdorong untuk ingin tahu, $28(84,84 \%)$ peserta didik merasa pembelajaran di laboratorium PAI menjadi lebih terdorong untuk berbuat jujur, dan $29(87,87 \%)$ peserta didik merasa pembelajaran di laboratorium PAI menjadi lebih terdorong untuk berperilaku sopan. Hanya ada satu pernyataan yang dijawab oleh sebagian peserta didik yang hanya mencapai kategori cukup baik, yaitu 21 $(63,63 \%)$ peserta didik merasa pembelajaran di laboratorium PAI menjadi lebih berani bertanya, ini menunjukkan penilaian yang belum mencapai kategori baik, sangat baik apalagi memuaskan.

Ketika peserta didik diminta penilaiannya terhadap pembelajaran yang dilakukan guru di laboratorium PAI SMAN 3 Bandung maka peserta didik menyatakan bahwa dalam pembelajaran PAI di laboratorium 32 (96,96\%) peserta didik menyatakan guru mendorong untuk lebih sering bertanya, $33(100 \%)$ peserta didik menyatakan guru memotivasi agar selalu ingin tahu, $33(100 \%)$ peserta didik menyatakan guru memotivasi untuk lebih berani berpendapat, dan $33(100 \%)$ peserta didik menyatakan guru membiasakan untuk bersikap sopan, jujur, saling menghormati, dan bertanggung jawab.

Terdapat tiga pernyataan yang dinilai oleh sebagian besar peserta didik dengan kategori sangat baik, yaitu pada pernyataan peserta didik tentang pembelajaran di laboratorium PAI guru menyampaikan tujuan pembelajaran sebelum pembelajaran PAI di lab dimulai, guru melatih melakukan percobaan, dan guru menggunakan teknologi informasi (seperti internet, komputer, laptop, televisi dan lain-lain) dalam mengajar di laboratorium PAI. Satu pernyataan yang dinilai oleh peserta didik dengan kategori baik, yaitu pada pernyataan peserta didik tentang pembelajaran di laboratorium PAI guru memotivasi lebih kreatif, dan satu pernyataan yang dinilai oleh peserta didik dengan kategori cukup baik, yaitu pada pernyataan peserta didik tentang pembelajaran di laboratorium PAI guru melatih melakukan pengamatan. Ini menunjukkan penilaian yang belum mencapai kategori baik, sangat baik apalagi memuaskan.

\section{Faktor Pendukung dan Kendala Pembelajaran di Lab PAI}

Faktor pendukung dan kendala pembelajaran pai di lab PAI SMAN 3 Bandung dapat dilihat melalui beberapa aspek, yaitu: (1) dari segi kebijakan internal sekolah terkait dengan pengelolaan laboratorium PAI, yaitu sekolah mendukung sepenuhnya untuk pengelolaan laboratorium PAI dalam mendukung mutu dan keberhasilan pembelajaran PAI; (2) dari segi sarana dan prasarana Lab PAI, SMAN 3 Bandung, untuk memenuhi kebutuhan sarana lab PAI, GPAI mengajukan permohonan kepada kepala sekolah dan wakil kepala sekolah melalui surat pengajuan dari GPAI sebagai pengelola lab PAI di sekolah. Solusi alternative yang dilakukan pengelola lab PAI, jika fasilitas yang dibutuhkan tidak tersedia dalam mendukung keberhasilan pembelajaran di laboratorium PAI di sekolah adalah dengan mengajukan pengadaan barang kepada wakasek sarana dan prasarana untuk segera memenuhinya. Adapun GPAI dengan sarana dan prasaran yang memadai, tentunya memanfaatkan keberadaan lab PAI untuk menunjang pembelajaran PAI di sekolah. 
Prasarana laboratorium PAI yang belum tersedia adalah ruangan belum kedap suara. Adapun sarana yang belum terpenuhi adalah AC dan Wastapel di ruangan Laboratorium PAI; (3) dari segi SDM laboratorium PAI di SMAN 3 Bandung, karena SDM nya adalah GPAI, tentu sangat mendukung karena lab PAI sebagai kebutuhan GPAI.

Di lihat dari kompetensi dan kualifikasi SDM laboratorium PAI, maka secara kompetensi sebagai GPAI berarti telah menguasai subtansi yang membuat lancarnya pembelajaran PAI. Namun secara kualifikasi sebagai tenaga laboran GPAI masih membutuhkan pemahaman tentang pengelolaan laboratorium PAI. Untuk SDM Laboratorium PAI di luar GPAI sebagi tenaga laboran boleh dibilang belum memenuhi kriteria jabatan yang harus ada di laboratorium PAI dan pembagian tugasnya yang dapat mengurangi kualitas pengelolaan laboratorium PAI. Hal ini diakui juga oleh GPAI bahwa kurangnya tenaga kebersihan, yang membersihkan lab PAI setiap selesai dipergunakaan, sehingga mereka merasa ke depan perlu tenaga laboran yang memahami fungsi laboratorium PAI di SMAN 3 Bandung; (4) dari segi pengelolaan lab PAI di SMAN 3 Bandung sudah dilakukan dan berusaha mengacu sesuai standar laboratorium PAI sebagaimana diamanatkan Kementrian Agama Nomor 211 tahun 2011.

Pengelolaan laboratorium PAI juga sudah berusaha dilakukan berdasarkan standar ISO, dan sejak tahun 2011 laboratorium PAI ini telah didaftarkan pada sistem ISO. Diantara kendala yang dihadapi dalam pengelolaan laboratorium PAI di sekolah, adalah adanya tantangan pengelolaan laboratorium PAI untuk pembelajaran PAI, yaitu tuntutan guru lain yang menghendaki adanya laboratorium untuk setiap mata pelajaran; dan (5) kendala dalam kegiatan pembelajaran PAI di laboratorium PAI yang dihadapi diantaranya adalah dengan system moving kelas adanya keterlambatan waktu beberapa menit dipakai perjalanan perpindahan dari kelas ke laboratorium PAI, dan ditemukan pula dalam waktu bersamaan ada dua atau lebih GPAI yang akan memakai laboratorium PAI, yang ini diperlukan pengaturan jadwal yang mengatur agar tidak terjadi kejadian tersebut, meski seringnya mengalah salah satu, atau digabung bila materinya sama.
Meski demikian hal ini menjadi kendala pembelajaran PAI di laboratorium PAI SMAN 3 Bandung.

\section{PENUTUP}

Beberapa kesimpulan dari penelitian ini adalah; (1) Dilihat dari sarana prasarana laboratorium PAI di SMAN 3 Bandung telah mencapai standar yang dikehendaki kesesuaiannya dengan PMA Nomor 211 tahun 2011, kecuali sarana yang belum tersedia berupa AC dan Wastapel; (2) Pemanfaatan laboratorium PAI di SMAN 3 Bandung, diantaranya sebagai: 1) Penunjang kegiatan pembelajaran PAI; 2) Sarana visualisasi konsep-konsep agama Islam; 3) Sarana praktik pembelajaran agama Islam; 4) Model imitasi pelaksanaan ibadah; dan 5) Pengolahan bahan dakwah; (3) Dilihat dari penilaian peserta didik tentang pengelolaan laboratorium PAI di SMAN 3 Bandung menunjukkan kebermanfaatan laboratorium PAI dalam meningkatkan mutu pembelajaran PAI di sekolah, bahkan menurut laporan peserta didik sangat merasakan manfaat dari laboratorium PAI. Namun diakui juga terhadap aspek yang perlu dimotivasi dalam pembelajaran di lab PAI yaitu aspek keberanian bertanya peserta didik dan kekuatan dalam melakukan pengamatan; dan (4) Tidak banyak factor kendala yang berarti dalam pengelolaan laboratorium PAI di SMAN 3 Bandung, dari segi sarana hanya belum ada AC dan Wastapel, dari segi SDM yaitu tenaga laboran di luar GPAI yang kurang memahami fungsi laboratorium, dan pengaturan jadwal yang masih bertabrakan antara satu guru dengan guru lain.

Berdasarkan kesimpulan tersebut di atas dapat direkomendasikan beberapa hal penting yaitu: (1) terhadap pencapaian standar sarana prasarana laboratorium PAI di SMAN 3 Bandung perlu dipertahankan dan ditingkatkan menjadi diatas standar, dan terhadap sarana yang belum tersedia berupa AC dan Wastapel perlu dianggarkan dan diadakan; (2) pemanfaatan laboratorium PAI di SMAN 3 Bandung telah fungsional, meski demikian intensitas pemanfaatannya perlu selalu ditingkatkan; (3) dilihat dari penilaian peserta didik tentang pengelolaan laboratorium PAI di SMAN 3 Bandung telah menunjukkan manfaat laboratorium PAI, kecuali terhadap aspek 
keberanian bertanya peserta didik dan kekuatan dalam melakukan pengamatan yang perlu ditingkatkan; dan (4) terhadap beberapa factor kendala dalam pengelolaan laboratorium PAI di SMAN 3 Bandung, kiranya perlu diperhatikan solusinya agar fungsi laboratorium PAI lebih maksimal.

\section{UCAPAN TERIMAKASIH}

Penulis mengucapkan banyak terima kasih kepada semua pihak yang telah memberikan kontribusi pada penelitian ini. Pertama kepada Kepala Puslitbang Pendidikan Agama dan Keagamaan, Badan Litbang dan Diklat, Kementerian Agama RI. Kedua kepada Kepala Sekolah SMAN 3 Bandung yang telah memberikan ijin kepada penulis untuk melakukan penelitian di sekolah tersebut, semua guru pendidikan agama Islam SMAN 3 Bandung sebagai pengelola laboratorium PAI, ternaga laboran PAI dan segenap siswa yang telah memberikan data dan informasi kepada penulis. Semoga penelitian ini bermanfaat adanya.

\section{DAFTAR PUSTAKA}

Achmadi. 1992. Islam Sebagai Paradigma Ilmu Pendidikan. Yogyakarta: Aditya Media.

Awan, Mustopha. (2000). Pengertian dan Fungsi Laboratorium. dalam https://wan mustafa.wordpress.com/2011/06/12/peng ertian-dan-fungsi-laboratorium/.

Daulay, Haidar Putra dan Nurgayapasa. (2012). Pendidikan Islam Dalam mencerdaskan Bangsa. Jakarta: Rineka Cipta.

Daulay, Haidar Putra, dan Nurgayapasa. (2012). Pendidikan Islam Dalam Mencerdaskan Bangsa. Jakarta: Rineka Cipta.

Decaprio, Richard. (2013). Tips Mengelola Laboratorium Sekolah. Yogjakarta: DIVA press.

Departemen Pendidikan dan Kebudayaan. 1995. Kurikulum Sekolah Menengah Umum Mata Pelajaran Pendidikan Agama Islam. Jakarta: Depdikbud.

Departemen Pendidikan Nasional. Kamus Besar Bahasa Indonesia. Jakarta: Balai Pustaka.
Kategones, Adi. (2017). Pengertian dan Manfaat Pendidikan Agama, dalam: http://dbagus.com/pengertian-danmanfaat-pendidikan-agama.

Keputusan Menteri Agama Nomor 211 Tahun 2011 tentang Pedoman Pengembangan Standar Nasional Pendidikan Agama Islam pada Sekolah. (Jakarta: Kementerian Agama, 2011).

Keputusan Menteri Agama Nomor 211 Tahun 2011 tentang Pedoman Pengembangan Standar Nasional Pendidikan Agama Islam pada Sekolah.

Khikmah, Baeti Ta'mirul. (2011). "Daya dukung laboratorium Biologi Madrasah Aliyah Negeri Di Kabupaten Tegal dalam Menunjang Pelaksanaan KTSP (Kurikulum Tingkat Satuan Pendidikan)", Skripsi. Semarang: Fakultas Tarbiyah IAIN Walisongo.

Marimba, AD. (1989). Pengantar Filsafat Pendidikan Islam. Bandung: Al-Ma'arif.

Nuha, Ulin. (2013). Standar laboratorium Pendidikan Agama Islam pada Sekolah. BAB I", dalam http://ulinnuhatuban. blogspot.com/2013/08/standar-

laboratorium-pendidikan-agama.

Peraturan Pemerintah Nomor 55 tahun 2007 tentang pendidikan Agama dan Keagamaan, Bab I Ketentuan Umum, Pasal 1.

Saleh, Abdul Rahman. (1976). Didaktik Pendidikan Agama. Jakarta: Bulan Bintang.

Sanchez, George I. (2003). Educational Psychology. Texas: College of Educational The University of Texas.

Sholihah, Rizka Maratush. (2013). "Efektifitas Pemanfaatan Laboratorium dalam Pembelajaran kimia di SMAN Se Kota Yogyakarta Tahun Ajaran 2012/2013". Skripsi, Fakultas sain dan Teknologi UIN Sunan Kalijogo.

Stufflebeam, Daniel, L. (1977). Educational Evaluation Decision Making. Itasca. Illinois: F.E. PeacockPubliser, Inc.

Sundari, Ratna. Evaluasi Pemanfaatan Laboratorium Pembelajaran Biologi di Madrasah Aliyah Negeri se-Kabupaten Sleman, dalam http://journal.uny.ac.id/ index.php/jpep/article/download/1427/12 15. 
Tusiyam, Siti Nur Hidayah. Wirjosoemarto.K, dkk. (2004). Teknik (2011).'Pemanfaatan Laboratorium Biologi untuk mencapai Standar Kompetensi Pembelajaran Biologi KelasXI IPA Semester I di MAN Kendal", Skripsi, Fakultas Tarbiyah IAIN Walisongo

Undang-undang No. 20 tahun 2003 tentang Sistem pendidikan Nasional, Bab I tentang Ketentuan Umum, h. 2.

Widyarti. 2005. Strategi Pengelolaan Laboratorium Biologi (Bahan. Pelatihan Manajemen. Laboratorium, Biologi, UNP). Laboratorium. JICA: IMSTEP.

Wiyanto. (2008). Menyiapkan Guru Sains Mengembangkan Kompetensi Laboratorium. Semarang: UNNES Pres, cet. 1 .

Worthen, Blaine R. dan James R. Sanders. (2011). A highly esteemed and comprehensive overview of program evaluation that covers common approaches, models, and methods. Western Michigan University; Utah State University. 